\title{
DEVELOPMENT OF GANODERMA HEBAL DRINK WITH BIOACTIVE COMPOUNDS
}

\author{
BY
}

\author{
SRIMA FERNANDO
}

Thesis submitted to in partial fulfillment of the requirements for the degree of

Master of Science

In

Food Science and Technology

Of the faculty of Graduate Studies

University of Sri Jayawardenapura

Sri Lanka

2012 


\section{DECLARATION}

The work described in the thesis was carried out by me under the supervision of Dr. Jagath Wansapala (The Department of Food Science and Technology University of Sri Jayawardenapura), report on this thesis has not been submitted in part of any institution for another degree

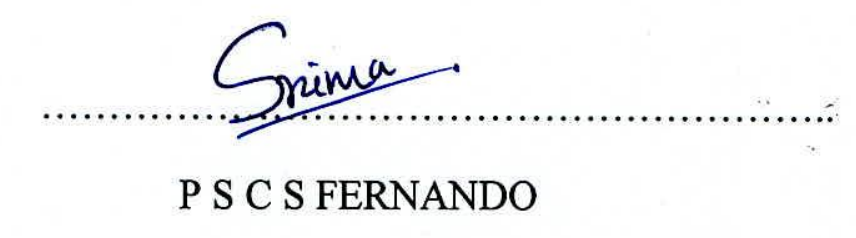


$\mathrm{I} / \mathrm{We}$ names of the supervisors certify that above statement made by the candidate is true and that this thesis is suitable for submission of the university for the purpose of evaluation.

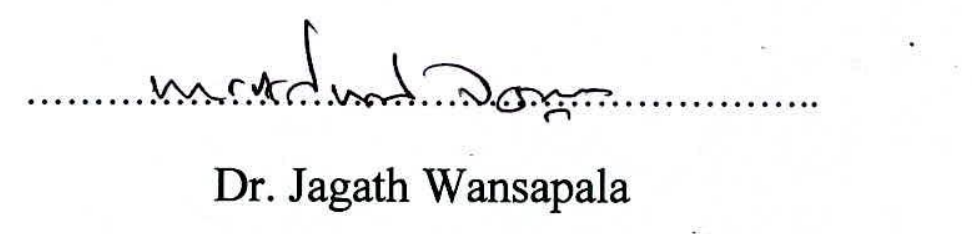

The Department of Food Science and Technology

University of Sri Jayawardenapura,

Gangodawila, Nugegoda,

Sri Lanka. 


\section{ACKNOWLEDGMENT}

I wish to my sincere thanks to Dr. Jagath Wansapala who was supervisor and guided to me achieve utmost knowledge,

A special word of thanks to all academic staff specially Dr.Nawarathna, and Dr. Rupika for coordinating me to complete the project with constant guidance.

Iwould like to express my thanks to all the technicians in foodscience laboratory of university of Sri jayawardenapura .

I am grateful to Mr. M A B V Bandaranayake the secretary to the ministry of Agriculture, fisheries, Animal production and Development, Minor irrigation and Agrarian Development-NWP.

I would like to express my special gratitude to my parents, my husband, and my kids for their unfailing support throughout this project. 


\begin{abstract}
Ganoderma lucidum known as Lingzhi in Chinese is commonly used Chinese medicines with excellent beneficial health effects. Triterpenes and polysaccharides are usually considered as its main phytochemical s. Modern pharmacologic studies have revealed that polysaccharides have multiple pharmacological activities.
\end{abstract}

The main aim of the present work was to develop a low cost Ganodermalucidum herbal drink with acceptable sensory attributes and less artificial additives especially for people who are suffering from various non communicable diseases on the background evidence of its attractive health benefits. This drink was prepared with Ganoderma extract, cinnamon oil, sucralose sweetener and citric acid. Sensory attributes,shelf life determination, physic-chemical analysis,microbiological analysis were the quality control parameters employed for Ganoderma product evaluation. The preservation was done solely by synergistic effect of natural anti microbial and antoxidativeactivity of Ganoderma extract, antmicrobial activity of cinnamon oil and low $\mathrm{pH}$ value of final beverage.The prepared Ganoderma herbal drink was highly adequate to get valuable bio active ingredients such Phenol,4-(1,1,3,3tetrametylbutyl), Hertriacontane ,Pentacosane, Linoleic acid, Ethyl oleate and Ergosterol for people who are suffering from various non communicable diseases.

The specific objective of present study was to analyze the proximate constituent of locally cultivated Ganodermalucidum. The major proximate constituent were moisture (4.31\%), Carbohydrate(13.72\%), total fat (4.84\%),total ash (1.67\%) crude protein $(24.84 \%)$ and crude fiber $(47.61 \%)$.

Keywords: Ganoderma lucidum, , Phytochemical, Ganoderma herbal drink, Quality control Synergistic effect, Preservation, bio active ingredients, non communicable disease. Proximate analysis, 
ABSTRACT IV

LIST OF FIGURES $\mathrm{X}$

LIST OF TABLES ..X

CHAPTER 1

INTRODUCTION 1

1.1 Background and justification .1

1.2 Objectives of the study. .5

\section{CHAPTER 2}

\section{LITERATURE REVIEW}

2.1 The botanical information of Ganoderma lucidum ............................ 6

2.1.1Classification.......................................................6

2.1.2 Habitat and Geography.............................................

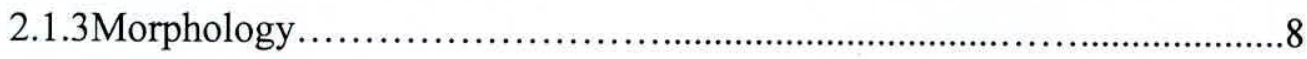

2.1.4 Life Cycle and Reproduction.........................................

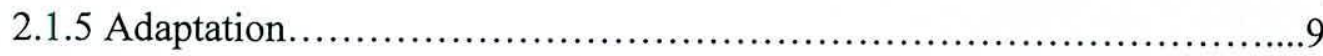

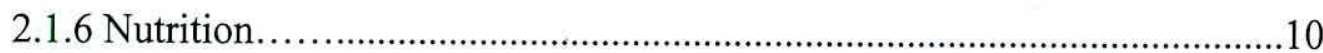

2.1.7 Harvest and Processing..........................................11

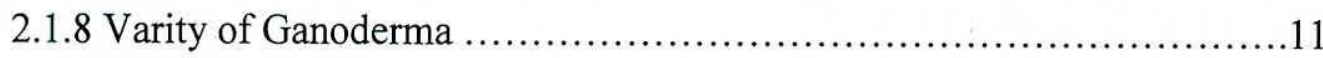

2.1.8.1 Black Reishi and red Reishi...................................12

2.2 The essence extract and raw form of Ganoderma ......................... 12 
2.3 Commercially available different forms of Ganoderma lucidum.

2.4 Composition of Ganoderma lucidum ..................................... 14

2.5 Phytochemicals of Ganoderma lucidum .................................. 16

2.6 Healthbenifits of Ganoderma lucidum .................................... 16

2.7 Bio active ingredients available in Ganoderma lucidium ...................... 17.

2.7.1 Polysaccharides.................................................... 17

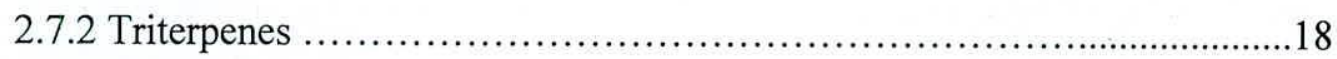

2.7.3 Other bio active ingredients ............................................ 19

2.8 Special featuers of Ganoderma lucidium ................................... 20

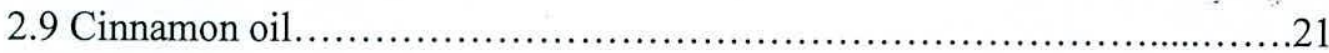

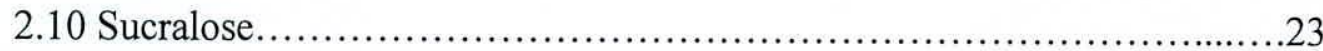

2.11 SLS 729:1985 specification for RTS drink and specification for oral herbal drinks by the European Medicines Agency ...........................23

2.12 Approval of herbal products in Sri Lanka...............................24

\section{CHAPTER 3}

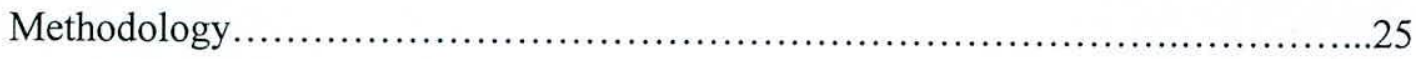

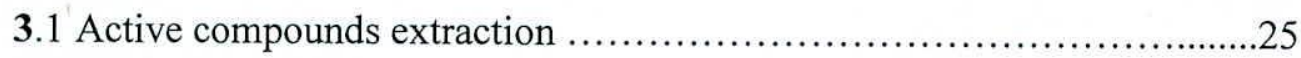

3.1.1 Selection of solvent for extraction of active compounds ................25

3.1.2 Selection of raw materials....................................25

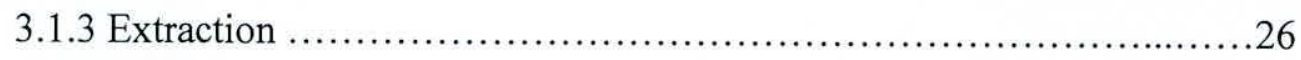


3.2.2 Formula development.

3.3 Sensory evaluation.

3.4 Shelf life determination 33

3. 4.1 Physico-Chemical Analysis. 34

3.4.1.1 pH:

3.4.1.2 Total soluble solids (TSS): .34

3.4.1.3 Titratable Acidity 34

3.4.2 Microbiology Analysis. 35

3.4.2.1 Determination of Yeast and Mould .35

3.4.2.2 Determination of Total plate Count. .37

3.4.2.3 Determination of Presumptive Coliform 38

3.4.3 Determination of sensory attributes .40

3.5 Determination of Heavy metals of finished beverage

3.6 Determination of phytochemical composituin.

3.7 Proximate Analysis of locally grown fresh Ganoderma 41

3.7 .1 Determination of Moisture content 41

3.7.2 Determination of Total Ash content. .42 
3.7.3 Determination of Total Fat content

3.7.4 Determination of Crude Fiber content .44

3.7.5 Determination of Crude protein 46

\section{CHAPTER 4}

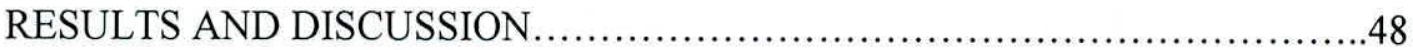

4.1 Active ingredient extraction.......................................48

4.2 Herbal drink formulation...............................................48

4.3 Results of Sensory evaluation......................................49

4.4 Shelf life determination of final herbal beverage .........................54

4.4.1 Physico- chemical Analysis......................................54

4.4.2 Microbial Analysis ............................................ 55

4.4.3 Analysis of Sensory Attributes........................................56

4.5 Results and discussion of Heavy Metal Analysisof Ganoderma drink........57

4.6 Results and discussion of phytochemical Analysis ..........................57

4.7 Results of Proximate Analysis of fresh Ganoderma .............................60

CHAPTER 5

CONCLUTION

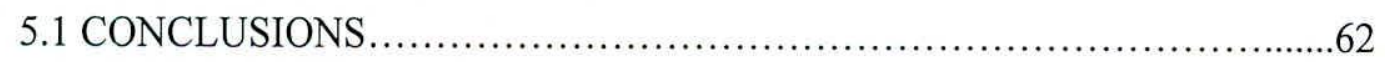

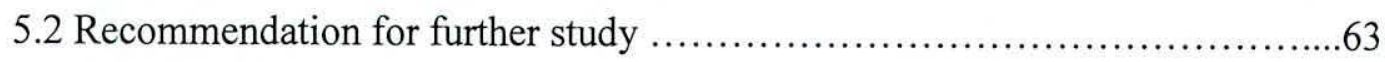




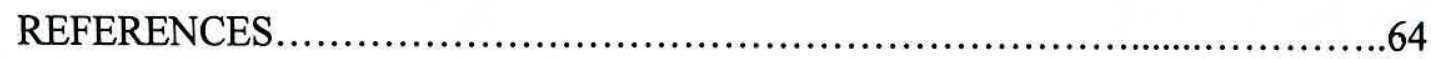

Appendix A............................................................... 70

Appendix B............................................................... 73

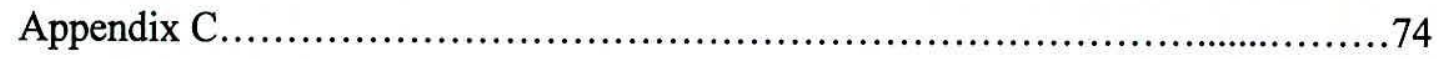

Appendix D................................................................... 75

Appendix E............................................................... 77 


\section{LIST OF FIGURES}

3.1 Flow diagram of Extraction of fresh Ganoderm.

3.2 Flow diagram of the process for making Ganoderma Herbal drink.

4.1 Kruskal-Wallis Analysis .51

4.2 Preference for sample 567 .52

4.3 GC-MS spectrem of Ganoderma lucidum 56

\section{LIST OF TABLES}

3.1 Formulation of sample. 27

3.2 Quantities of ingredients for making $100 \mathrm{ml}$ of Ganoderma herbal drink. 28

4.1 Result of Physico- chemical Analysis. .53

4.2 Result of Microbial Analysis .54

4.3 Results of Sensory Attributes. .55

4.4 GC-MS analysis revealed the presence of phytochemical components in Ganoderma herbal drink .57

4.5 Proximate test results .59 


\section{CHAPTER 1}

\section{INTRODUCTION}

\subsection{Background and justification}

Human beings require a balanced diet to grow, reproduce and maintain good health. Over thousands of years, man developed meal patterns to suit this basic purpose. However, with industrial revolution setting in fast, the lifestyle changed to a busy, hectic one that made man run out of time. To save time and to keep up with the pace, he started producing so many kinds of artificial instant foods and beverages which compromised the concept of balanced diet. Today, both nationally and globally, there is a very high prevalence of non-communicable diseases such as cancer, hypertension, diabetes mellitus, dyslipideaemia and also diseases of kidneys, liver and gastrointestinal tract. According to many researchers majority of these are attributed to bad food habits. As a result, there is an ongoing attempt to reintroduce natural food, beverage and medicine habits which have been widely used throughout the history of mankind for the general promotion of health and longevity. Nature has been a source of medicinal agents for thousands of years and an impressive number of modern drugs too have been isolated from natural sources. Many of these isolations have been based on the natural ingredients used in traditional medicine (Abraham and Thomas, 2012). Traditional medicines are used in large scale for health care in the national health care system. Globally, herbal medicines serve the health needs of a large majority of the world's population. In general, more than $65 \%$ of the global population uses medicinal plants as a primary health care modality (Kamaraj et al., 2012). The emergence of new infections caused by previously unknown pathogens, increasing incidence of resistance to antimicrobial agents, high costs of synthetic drugs and their 
voracious side effects have led to a global increase in the use of traditional medicines. Natural medicinal products have come from various sources including terrestrial vertebrates, invertebrates, plants, microorganisms and also marine organisms. Numerous investigations have proved that these plants and organisms contain a diversity of bioactive compounds such as tannins, alkaloids, flavonoids, terpenoids, phenols, etc. (Chitemerere and Mukanganyama, 2011). Plants have been a major focus of investigations for novel biologically active compounds. Especially, filamentous fungi are producers of some of the most powerful secondary metabolites which have been developed into therapeutic agents (Roberts, 2004). These bioactive compounds have various direct effects on a living organism. These effects may be positive or negative depending on the substance, the dose or the bioavailability.

Ganoderma lucidum is a mushroom which belongs to kingdom fungi, phylum Basidiomycota, class Agariomycetes ,order Ganodermataceae, genus Ganoderma and species Ganoderma lucidum. It is a large, dark mushroom with a glossy exterior and a woody texture. The Latin word lucidus means "shiny" or "brilliant" and refers to the varnished appearance of the surface of the mushroom. It is commonly referred to as Lingzhi in China and Reishi in Japan. The name Lingzhi represents a combination of spiritual potency and essence of immortality, and is known as the "herb of spiritual potency" symbolizing success, well-being, divine power, and longevity. It has a long been used for promoting health and longevity in China, Japan, and other Asian countries. Ganoderma lucidum has been used for hundreds of years as a health promotion and treatment strategy. Many of these applications of G. lucidum are were based largely on anecdotal evidence, traditional use, and cultural mores. However, recent reports provide scientific support to some of the ancient claims of the health benefits of Ganoderma with only a few adverse side effects. Owing to its irregular 
distribution in the world and to an increasing demand for G. lucidum as a medicinal herb, attempts were made to cultivate the mushroom (Chang and Buswell 2008). Artificial cultivation of $G$. lucidum has been achieved using substrates such as grain, sawdust, wood logs (Chang and Buswell 1999; Wasser 2005; Boh et al. 2007), and cork residues (Riu, Roig, and Sancho 1997).

Most mushrooms are $90 \%$ water by weight. For G. lucidum, the remaining $10 \%$ consists of $26-28 \%$ carbohydrate, $3-5 \%$ crude fat, $59 \%$ crude fibre, and $7-8 \%$ crude protein ( Mau JL, Lin HC, Chen2001)In addition, G. lucidum contains a wide variety of bioactive constituents such as terpenoids, steroids, phenols, glycoproteins, and polysaccharides, fatty acids and nucleosides. .Numerous authors have shown that triterpenes and polysaccharides are the major physiologically active components of $G$. lucidum for its medicinal use (Boh B, Berovic M, Zhang J, Zhi-Bin L). Two species of Ganoderma, G. sinense and G. lucidum, are used as Lingzhi in China. Howerver, the content of triterpenoids and polysaccharides, main actives compounds, are significant different, though the extracts of both G. lucidum and $G$. sinense have antitumoral proliferation effect. It is suspected that other compounds contribute to their antitumoral activity. Sterols and fatty acids have obvious bioactivity.

These bio active ingredients have been known to have numerous pharmacological effects including immuno-modulating, anti-inflammatory, anti-cancer, anti-diabetic, anti-oxidative and free radical-scavenging, anti microbial and anti HIV-1 and antiaging effects. Among cultivated mushrooms, G. lucidum is unique in that it has got more pharmaceutical rather than nutritional value. According to its species and variety, Ganoderma differs in levels of the bioactive ergosterol and some 
triterpenoids, fattyacids and sterols. Various environmental conditions that are used to grow this mushroom also can greatly affect its chemical composition. S o there was a objective to find out the nutritional composition of Ganoderma lucidum cultivated in Sri Lanka.

Although Ganoderma lucidum possesses this overwhelming medicinal value, its nutritional value may still be considered very important. As Reishi is a polypore with high fiber content, it is not eaten as it is, but cut into pieces and made into an extract. The extraction is done by using organic solvents and water. Polysaccharide compounds (carbohydrates and fiber) tend to be found in the water-soluble fragment and organic compounds are found in ethanolic fragment as they are fat soluble. A variety of commercial $G$. lucidum products are available in various forms, such as powders, dietary supplements, and tea. These are produced from different parts of the mushroom, including mycelia, spores, and fruit body. Effective dosage of the extract ofGanodermalucidum varies in treatment of various ailments. The standard dose of Ganodermalucidum depends on the form of the supplement. The effective dosage for the basic extract is $1.5 \mathrm{~g}-9 \mathrm{~g}$ per day (Teow sun soo, 1996). The most popular dose is $5.2 \mathrm{~g}$, taken in three doses of $1.8 \mathrm{~g}$. The amount and percentage of each bio active component can be very diverse in commercial products. Such variation can occur for several reasons including differences in the species of mushroom used and differences in production method. Triterpenoid content of commercial products range from undetectable to $7.8 \%$ and polysaccharide content ranges from $1.1-5.8 \%$ (Boh et al 2007,Zhou et al 2007). 